\title{
Tambores de Luz - Estação (Campinas)
}

\section{Light drums - Station (Campinas, SP, Brazil),}

\section{Dirceu da Costa Maués}

Universidade Federal de Minas Cerais

\section{Resumo}

As fotografias apresentadas neste ensaio funcionam, ao mesmo tempo, como imagens documentais e desdobramento poético das instalações realizadas na antiga estação ferroviária central de Campinas (SP), durante o $10^{\circ}$ Festival Hercule Florence de Fotografia, em abril de 2017 : uma intervenção no espaço público que propõem um diálogo com a paisagem urbana local através de efêmeras imagens que se projetam invertidas no interior do dispositivo e deslocam a percepção do observador transeunte.

Palavras-chave: Intervenção Artística; Instalação; Fotografia; Câmera Obscura; Festival Hercules Florence de Fotografia.

\section{Abstract}

The photographs presented in this essay work at the same time as documentary images and poetic unfolding of the installations presented at the old central railway station of Campinas (SP) during the 10th Hercule Florence Photography Festival in April 2017: an intervention in the public space which propose a dialogue with the local urban landscape through ephemeral images that project inverted inside the device and displace the perception of the passerby observer.

Keywords: Artistic Intervention; Instalation; Photography; Obscure Camera; Hercules Florence Festival. 


\section{Fotografia, Arte e História \\ na atualidade: relações praticadas}

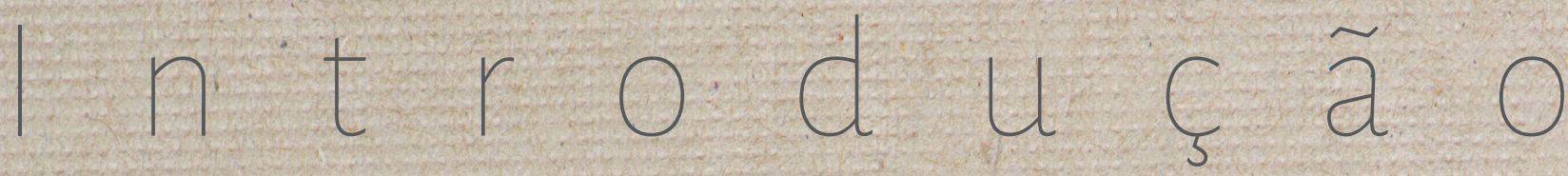

ambores de Luz - Estação foi uma instalação realizada na antiga estação ferroviária central de Campinas (SP), durante o $10^{\circ}$ Festival Hercule Florence de Fotografia, em abril de 2017. A instalação era composta de dois conjuntos de 28 tambores de metal. Os tambores funcionavam como câmeras obscuras e, dentro deles, era possível visualizar imagens projetadas sobre um anteparo de papel vegetal: imagens invertidas (de ponta cabeça) do espaço que se encontra à frente dos tambores. Cada conjunto de 28 tambores foi posicionado em uma das extremidades do galpão que integra o prédio da antiga estação: um apontando para o nascente e o outro para o poente. Eram como marcos de orientação espacial. Cada conjunto formava um grande painel triangular de imagens circulares.

O projeto inicial era diferente, havia sido pensado à distância, baseado em algumas imagens do local. Estar presente e perceber in loco as dimensões do espaço, suas relações reais com o corpo, a dinâmica desse espaço, o fluxo dos transeuntes, o fluxo da luz, foi imprescindível para pensar como criar um trabalho que dialogasse melhor com sua arquitetura.

Este trabalho faz parte de uma série de instalações e/ou intervenções urbanas intitulada "[in] versões na paisagem": foi como denominei os primeiros trabalhos de intervenções com câmeras escuras que foram realizados em Brasília, em 2013. Essas intervenções se aproximam, algumas vezes, da noção de instalações in situ ou site specific, pois propõem um diálogo com a paisagem local, com um ambiente ou com a especificidade de determinados espaços. Há um planejamento, de tal forma que o trabalho dialogue com os elementos da arquitetura e da paisagem do espaço que a envolve.

Estes trabalhos apresentam recortes específicos da paisagem e são geralmente instalados em lugares de passagem: ora aproveitando os limites dos espaços arquitetônicos que definiam uma passagem entre áreas internas e externas; ora buscando os limites, nos lugares abertos da cidade, entre espaços de sombra e espaços de luz.

A imagem provoca uma reação de encantamento e magia que parece estar relacionada à nos- 
sa crença de que apenas os dispositivos tecnológicos considerados altamente complexos são capazes de produzir imagens. Há, portanto, uma certa incredulidade com processos tecnológicos mais simples ou precários. É justamente dessa incredulidade que surge 0 espanto. Neste sentido, vivenciar a experiência da câmera obscura em um encontro casual na cidade provoca nesse expectador-transeunte certos deslocamentos. Não apenas um deslocamento em nosso modo de ver os dispositivos, mas o deslocamento que segundo Karina Dias (2010, p.114), se faz necessário para termos a experiência da paisagem, para vislumbrarmos "uma nova configuração do espaço de sempre". ${ }^{1}$

Toda imagem do horizonte, segundo Anne Cauquelin (2011, p.103), contém essa ideia de deslocamento, de um salto para o além, para o desconhecido, para um outro mundo:

[...] todo horizonte é uma incitação à viagem para um além, desconhecido ou outro 'mundo'. Ao separar o próximo do distante, a linha de horizonte oferece ao pensamento um dado precioso, pois permite expressar visível, plasticamente, o 'salto' no desconhecido que precisa ser

1 DIAS, Karina. Entre visão e invisão: paisagem: por uma experiência da paisagem no cotidiano. Brasília: UNB, 2010, p.114.
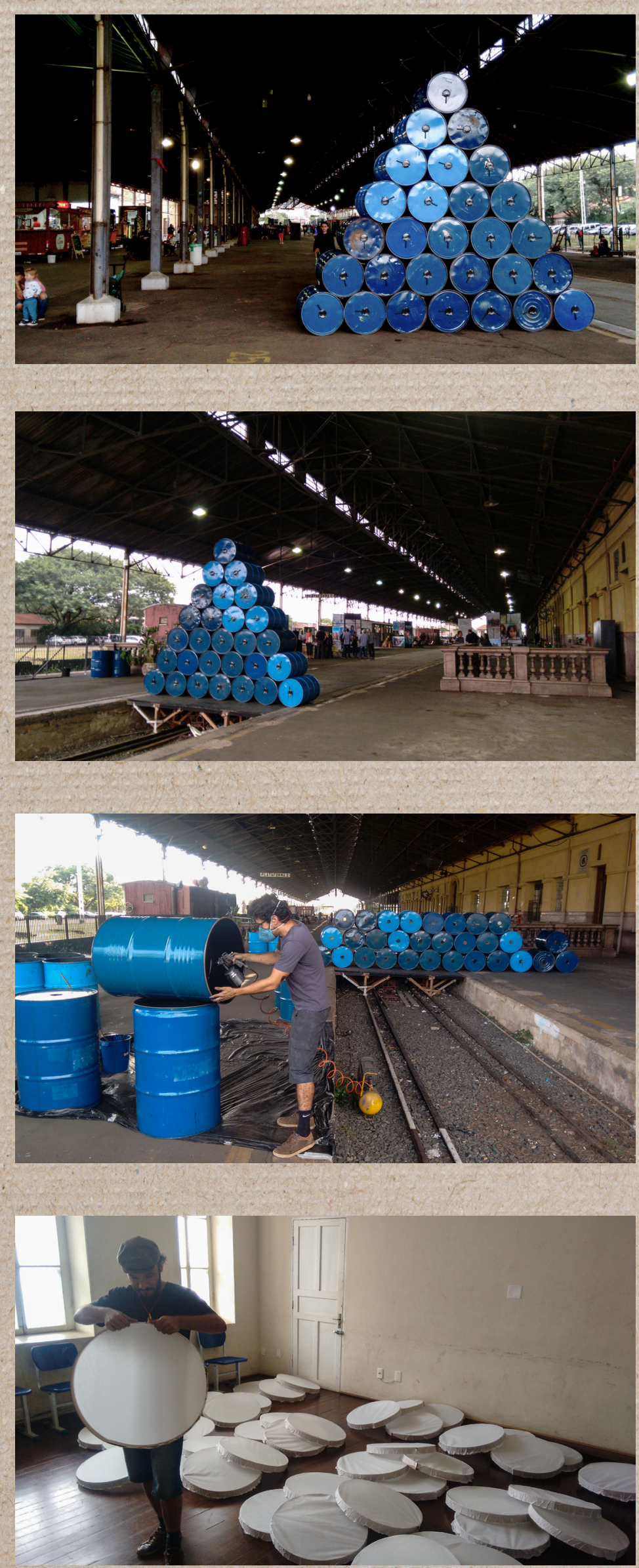


\section{Ensaio Visual $\begin{array}{r}\text { Fotografia, Arte e Fistória } \\ \text { na atualidade: relaçóes praticadas }\end{array}$}

dado[...] A imagem do horizonte está, assim, ligada a um "além" da representação, um "fora" ou transbordamento da realidade das coisas como elas são. ${ }^{2}$

A imagem do horizonte sempre indica que existe algo para além de onde nossa vista alcança, que há em nossa realidade sempre uma possibilidade de transbordamento.

O horizonte visto de ponta cabeça talvez indique que o mundo pode ser observado de um ponto de vista radicalmente diferente. Para quem está aberto a esse deslocamento, a inversão da paisagem pode operara inversão de um ponto de vista, não apenas sobre o tecnológico, mas sobre os vários níveis de realidade do mundo. O mundo visto, literalmente, de ponta cabeça dentro da câmera obscura pode funcionar perfeitamente como metáfora para a situação atual político-econômica do país, ou para muitas das inversões de valores humanos no mundo globalizado:

A intervenção, por outro lado, desloca o próprio conceito de fotografia, pois, nesse sentido, a fotografia como ato fotográfico não se completa, não se fecha na produção de uma imagem-objeto com objetivo de ser apresentada em um espaço

2 CAUQUELIN, Anne. No ângulo dos mundos possíveis. São Paulo: Martins Fontes, 2011, p.103.
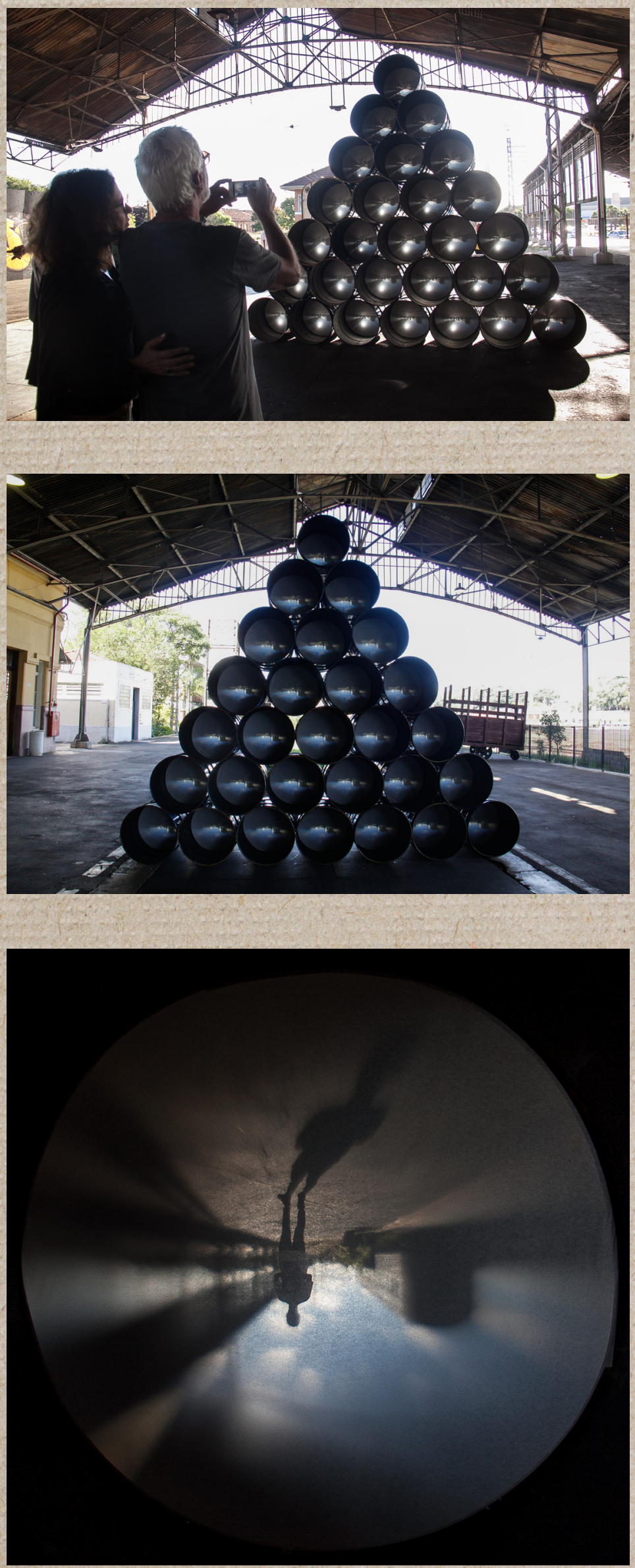

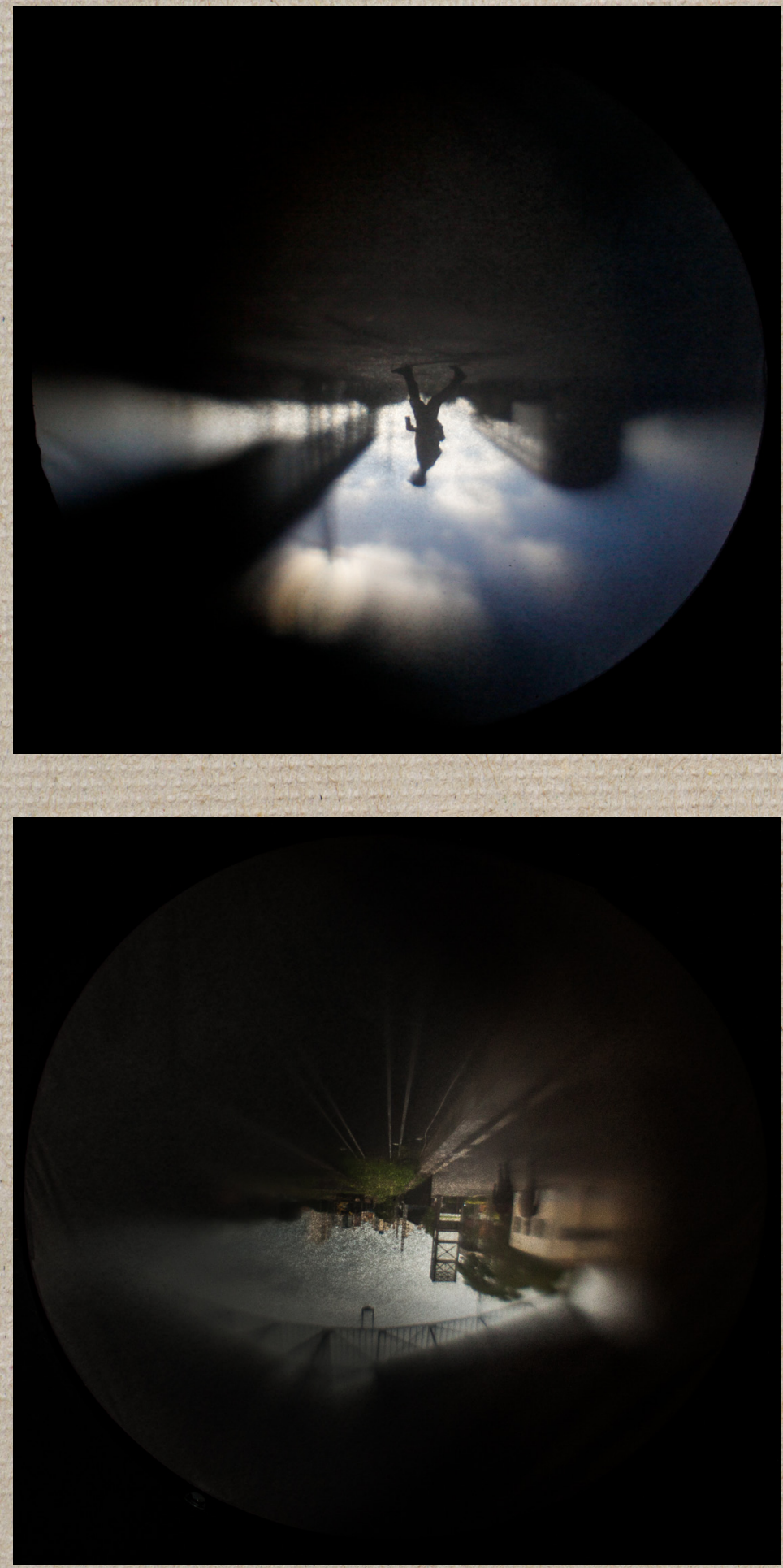

expositivo, ou ser utilizada em alguma publicação, para ser vista. A imagem dentro da câmera - esse recorte preciso da paisagem determinado pelo olhar do fotógrafo - é efêmera: é imagem-devir, imagem desejante; imagem que surge no interior de uma câmera que não mais fotografa, apenas mostra, apresenta um recorte do olhar. A imagem, agora, é o elemento de contato entre o olhar do fotógrafo e o olhar do transeunte que caminha pela cidade. E a intervenção pode ser pensada, então, como uma forma de ajanelar o cotidiano, despertando em nossa visão o movimento necessário para olharmos com outros olhos o que nos é habitual:

Ajanelar o cotidiano é trazer à superfície da visão fragmentos da paisagem, talvez, longínquos e esquecidos, é desenvolver uma prática do banal que suscite o desejo de ver. É despertar a nossa visão quase sempre esquecida, colocando-a em movimento para olhar o habitual, (des)conhecer o (in) comum, olha-lo novamente, uma vez mais... ${ }^{3}$

Imagem efêmera em duplo sentido. Por um lado, nada se move internamente, é semelhante a uma fotografia impressa; por outro, se prestarmos bastante atenção, perceberemos seus movimentos internos. Aí, então, a imagem transborda: é puro movimento em tempo real. Mas, materialmente, não é uma coisa nem outra. Apenas puro desejo, sem memória, de fixar-se sobre um suporte sensível. Puro desejo que alimentou os sonhos de todos os pioneiros da fotografia no

3 DIAS, Karina. Entre visão e invisão: paisagem: por uma experiência da paisagem no cotidiano. Brasília: UNB, 2010 , p. 290. 
século XIX e que agora alimenta nossos próprios encantamentos em relação à efemeridade e ilusão dessa imagem.

Câmera obscura: magia! Simples magia de deslocamento, de expectativa, ou da falta de qualquer expectativa. Um encontro íntimo, uma singularidade: essa imagem mágica que se projeta no interior de uma caixa, ou dentro de um tambor de latão. "E é tão colorida! parece uma TV invertida!”, alguém falou ao observar as imagens no interior de uma das câmeras obscuras. "São dois mundos, né?! é engraçado! as pessoas andam flutuando de ponta cabeça, mas não caem. E quando eu vou para o outro lado, eu fico de ponta cabeça, mas a minha cerveja não derrama!", comentou um outro rapaz que tinha parado para olhar as imagens enquanto bebia sua cerveja. "Parece uma fotografia viva", retrucou outra pessoa.

Nesse mundo tão saturado de imagens, produzidas por aparelhos tecnológicos cada vez mais sofisticados, as imagens das instalações com câmeras obscuras nos transportam para outro tempo, um horizonte reverso: 0 tempo de Nicéphore Niépce, Louis Daguerre, Hercule Florence, Fox Talbot, e de todos os outros precursores da fotografia que juntos ardiam em desejos pela fixação da mágica imagem que se projetava no interior da câmera obscura. Segundo Geoffrey Batchen (2004, p.7):

[...] Arder em desejos, provém de uma carta escrita por Louis Dàguerre em 1828, na
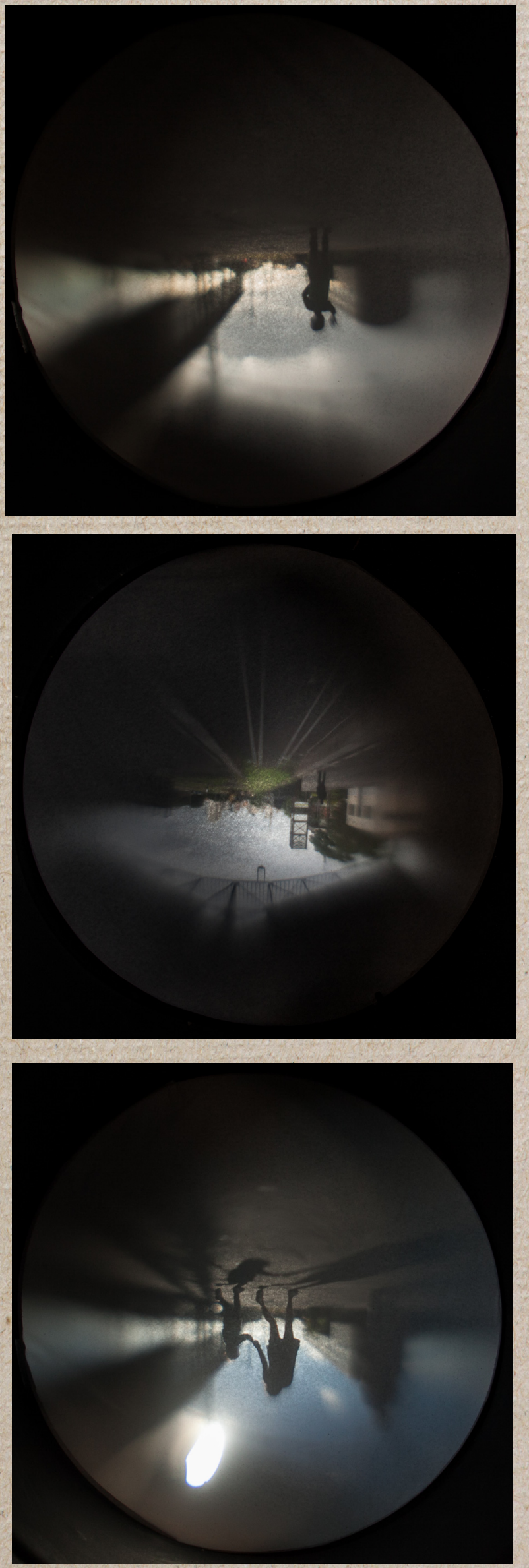

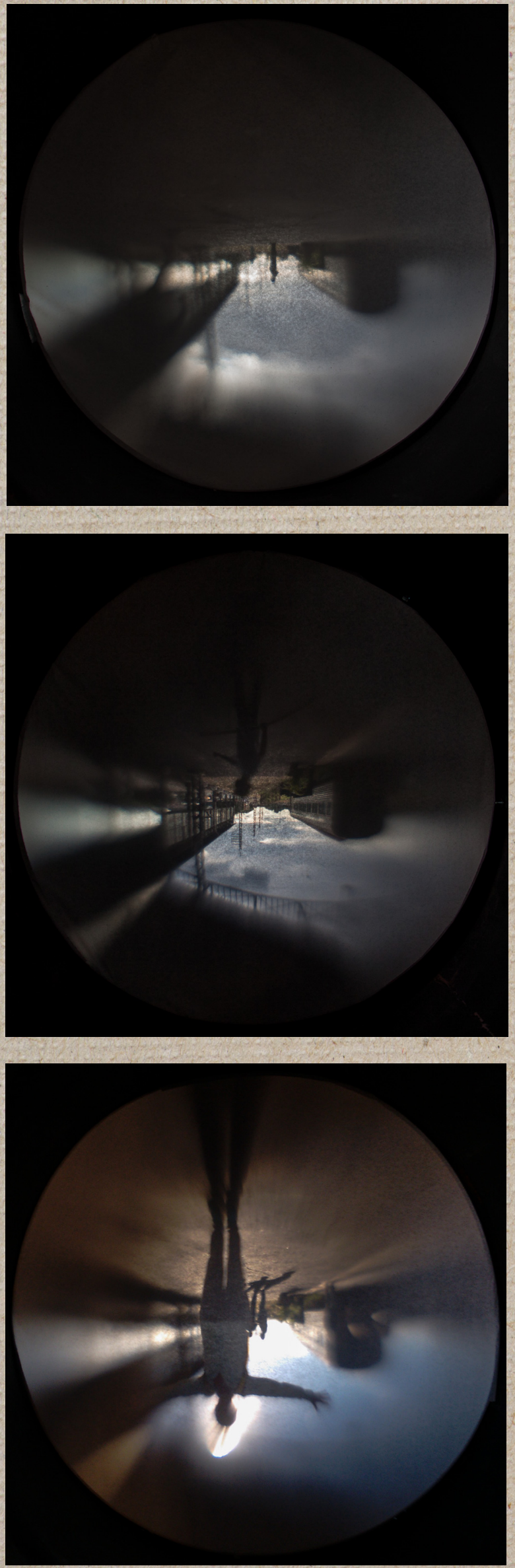

qual disse a seu sócio Nicéphore Niépce: "ardo em desejos ao ver teus experimentos tomados da natureza". ${ }^{4}$

Em tempos tecnológicos em que a imagem, depois de ter se fixado sobre o papel fotográfico, transbordou e materializou-se também para um mundo virtual de segunda ordem, a experiência da câmera obscura refaz um caminho de volta, em direção à imaterialidade, ao desejo que precedia a imagem fotográfica como a conhecemos - ou a conhecíamos alguns anos atrás. Reversa paisagem: o mundo de ponta cabeça. Desejos ardem em imagens. Desejos de fixar desejos em desejos inversos, em mundos paralelos: efêmera imagem.

4 BATCHEN, Ceoffrey. Arder em deseos: la concepción de la fotografia. Barcelona: Gustavo Cili, 2004, p. 7 (tradução livre do autor). 